\title{
Dissociation between Dorsal and Ventral Hippocampal Theta Oscillations during Decision-Making
}

\author{
Brandy Schmidt, ${ }^{1}$ James R. Hinman, ${ }^{1}$ Tara K. Jacobson, ${ }^{1}$ Emily Szkudlarek, ${ }^{1}$ Melissa Argraves, ${ }^{1}$ Monty A. Escabí, ${ }^{1,2,3}$ \\ and Etan J. Markus ${ }^{1}$ \\ Departments of ${ }^{1}$ Psychology, ${ }^{2}$ Biomedical Engineering, and ${ }^{3}$ Electrical and Computer Engineering, University of Connecticut, Storrs, Connecticut 06269
}

Hippocampal theta oscillations are postulated to support mnemonic processes in humans and rodents. Theta oscillations facilitate encoding and spatial navigation, but to date, it has been difficult to dissociate the effects of volitional movement from the cognitive demands of a task. Therefore, we examined whether volitional movement or cognitive demands exerted a greater modulating factor over theta oscillations during decision-making. Given the anatomical, electrophysiological, and functional dissociations along the dorsalventral axis, theta oscillations were simultaneously recorded in the dorsal and ventral hippocampus in rats trained to switch between place and motor-response strategies.

Stark differences in theta characteristics were found between the dorsal and ventral hippocampus in frequency, power, and coherence. Theta power increased in the dorsal, but decreased in the ventral hippocampus, during the decision-making epoch. Interestingly, the relationship between running speed and theta power was uncoupled during the decision-making epoch, a phenomenon limited to the dorsal hippocampus. Theta frequency increased in both the dorsal and ventral hippocampus during the decision epoch, although this effect was greater in the dorsal hippocampus. Despite these differences, ventral hippocampal theta was responsive to the navigation task; theta frequency, power, and coherence were all affected by cognitive demands. Theta coherence increased within the dorsal hippocampus during the decision-making epoch on all three tasks. However, coherence selectively increased throughout the hippocampus (dorsal to ventral) on the task with new hippocampal learning. Interestingly, most results were consistent across tasks, regardless of hippocampal-dependent learning. These data indicate increased integration and cooperation throughout the hippocampus during information processing.

\section{Introduction}

Hippocampal theta oscillations (4-12 Hz) (Buzsáki, 2002) support mnemonic processes (Mizumori et al., 1990; M'Harzi and Jarrard, 1992; Klimesch, 1999; O’Keefe and Burgess, 1999; Kahana et al., 2001; Raghavachari et al., 2001; Hyman et al., 2003; Hasselmo, 2005; Düzel et al., 2010). Theta oscillations may also facilitate decision-making. Theta power has been shown to increase at the choice point, the purported location of cognitive functions, such as memory retrieval and decision-making (DeCoteau et al., 2007; Montgomery et al., 2009). Similar reports have shown increased

Received June 18, 2012; revised Feb. 6, 2013; accepted Feb. 23, 2013.

Author contributions: B.S., T.J., and E.J.M. designed research; B.S., E.S., and M.A. performed research; B.S. and M.A.E. contributed unpublished reagents/analytic tools; B.S., J.R.H., T.J., E.S., M.A., and E.J.M. analyzed data; B.S. and E.J.M. wrote the paper.

This research was supported by the University of Connecticut Research Foundation. We thank Dr. Elizabeth Ciurylo, Emma Zhang, Jia Li Lu, and Benjamin Gruenbaum.

The authors declare no competing financial interests.

Correspondence should be addressed to Dr. Etan J. Markus, Department of Psychology, University of Connecticut, 406 Babbidge Road, Unit 1020, Storrs, CT 06269. E-mail: etan.markus@uconn.edu.

B. Schmidt's present address: Department of Neuroscience, University of Minnesota, Minneapolis, MN 55455.

J.R. Hinman's present address: Center for Memory and Brain, Department of Psychology, Boston University, Boston, MA 02215.

T. Jacobson's present address: Department of Cognitive, Linguistic, and Psychological Sciences, Brown University, Providence, RI 02912.

DOI:10.1523/JNEUROSCI.2915-12.2013

Copyright $\odot 2013$ the authors $\quad 0270-6474 / 13 / 336212-13 \$ 15.00 / 0$ dorsal hippocampal (dHipp) theta coherence at the choice point (Montgomery et al., 2009).

In addition to cognitive/mnemonic processes (Klimesch, 1999; Düzel et al., 2010), theta oscillations are modulated by volitional movement. Theta power is positively correlated with running speed (Vanderwolf, 1969; Hinman et al., 2011). Whether volitional movement or cognitive demands exert a greater modulating factor over theta oscillations is a matter of debate (Kelemen et al., 2005; Voss et al., 2011).

Although theta oscillations are traditionally recorded in the dHipp, anatomical (Amaral and Lavenex, 2007), electrophysiological (Jung et al., 1994; Kjelstrup et al., 2008), activational (Satvat et al., 2011; Schmidt et al., 2012), and functional (Moser and Moser, 1998) dissociations exist along the septotemporal (dorsal-ventral) axis. There is currently a controversial debate as to whether the hippocampus is functionally homogenous or if there is a spatial/memory-emotional/stress dissociation along the septotemporal axis. Lesion studies suggest that the dHipp supports spatial functioning (Moser and Moser, 1998) and the ventral hippocampus (vHipp) supports emotional processes (Kjelstrup et al., 2008). In contrast, other studies report that spatial processes are supported throughout the septotemporal axis (de Hoz et al., 2003; Loureiro et al., 2012). This functional dissociation is similarly reflected in hippocampal anatomy. The dHipp receives visual-spatial input from the dorsal entorhinal cortex (Dolorfo and Amaral, 1998), whereas the vHipp receives emo- 


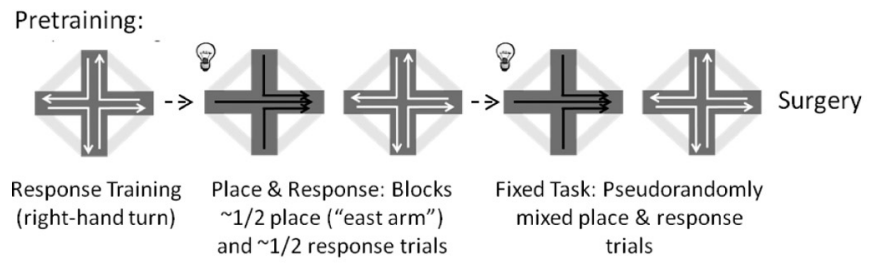

Response Training Place \& Response: Blocks and $\sim 1 / 2$ response trials

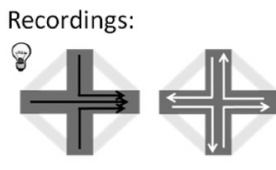

Retraining on Fixed Task: Pseudorandomly mixed place \& response trials

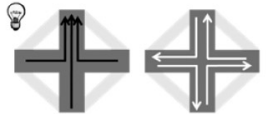

Novel Place Task: Mixed place and response trials place and response trials with with a novel place arm a stationary place arm \& each day

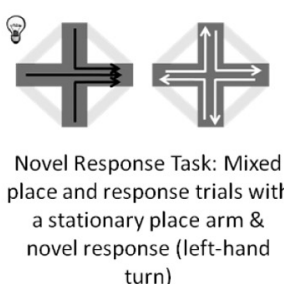
turn)

Figure 1. Training paradigm. During pretraining rats were first trained on a response task (right turn). Rats were then trained on blocks of place and response trials. Place trials were cued with a flashing light. Next rats were trained on the fixed task with no more than three consecutive trials of the same navigation strategy. After surgery and recovery, the rats were retrained on the fixed task. Rats then commenced the novel place task. Rats were trained to run to a new place goal arm each day during the place trials, while continuing to make a right turn on the response trials. Last, rats commenced the novel response task. Rats were trained to make a left turn (rather than a right turn) during the response trials and go to the original place arm (east arm) during the place trials.

tional information from the amygdala (Risold and Swanson, 1996). To date, few studies have simultaneously recorded theta oscillations from the dHipp and the vHipp (but see Royer et al., 2010; Hinman et al., 2011; Patel et al., 2012). No study, to our knowledge, has done so in rats trained on different spatial tasks.

We simultaneously recorded from the dHipp and the vHipp in rats trained to continuously switch between place and response strategies. dHipp lesions affected performance during place, but not response, trials (Jacobson et al., 2012). Several consistent dissociations were noted along the septotemporal axis across tasks. The relationship between theta power and running speed decoupled in the dHipp during the decision epoch, but not in the vHipp. Theta power increased during the decision epoch in the dHipp, but decreased in the vHipp. This effect was strongest when learning the daily task and decreased as the task was acquired. dHipp and vHipp theta frequency increased during the decision epoch, though the effect was greater in the dHipp. Theta coherence increased within the dHipp during the decision epoch on all tasks. In contrast, theta coherence only increased all along the septotemporal axis on the task with new hippocampal learning.

\section{Materials and Methods}

Subjects. Eight male Fisher 344 rats (Harlan) $8.0 \pm 1.0$ (mean \pm SEM) months old at the start of training were used. Rats were housed in a vivarium maintained at $\sim 22^{\circ} \mathrm{C}$ and kept on a $12 \mathrm{~h}$ light/dark cycle. Rats were housed individually in clear Plexiglas cages $(46 \times 20 \times 23 \mathrm{~cm})$ with pine bedding and ad libitum access to water. Rats were maintained at $\sim 85 \%$ of their ad libitum weight during the experiment. All procedures were performed in accordance with the University of Connecticut's Institutional Animal Care and Use Committee.

Apparatus. A black Plexiglas runway $(120.7 \times 10.2 \mathrm{~cm})$ was used for pretraining. Training and recording were on a modified version of the plus maze. The plus maze was constructed of black Plexiglas $(112.4 \mathrm{~cm}$ long, $10.8 \mathrm{~cm}$ wide, $15.9 \mathrm{~cm}$ off the table). Four moveable black Plexiglas runways were constructed to form a perimeter around the plus maze.

Runway pretraining. Rats were trained to run back and forth on a linear runway for chocolate sprinkle rewards daily for $10 \mathrm{~d}$. The daily training sessions continued up to $10 \mathrm{~min}$ on the maze or until the rat completed 10 trials in 5 min.

Behavioral procedure. Each training session consisted of 32 correct trials or $20 \mathrm{~min}$, whichever came first, for the rats implanted in dorsal hippocampus only $(n=4)$ and 40 correct trials or $30 \mathrm{~min}$ for the rats implanted in both dorsal and ventral hippocampus $(n=4)$. Training continued until a criterion of 2 consecutive days at $80 \%$ correct was reached (random chance was $33 \%$ ), after which the rat proceeded to the next training paradigm.

Fixed place (spatial reference memory) and response task (Fixed Task). Training procedures were as described by Schmidt et al. (2009) and Jacobson et al. (2012). Rats were initially trained on a response task ("right turn") (Fig. 1). Each trial ended after the rat entered a maze arm, whether or not a correct choice was made. Perimeter runways connecting the arms were raised providing a path to the next start location (if an error was made, the rat was guided to the original start arm to repeat the trial until successful). Once the rat reached criterion for response training, the place strategy was introduced (Fig. 1). During place and response block training the sessions were broken up approximately into halfplace/half-response blocks ( $\sim 16$ trials each), such that animals switched strategies one or two times. Again, during the response block, rats were rewarded for making a right turn on the maze. During the place-block trials (spatial reference memory) rats were rewarded for going to the same "place" (east arm) regardless of the start arm. The place trials were differentiated from the response trials by a flashing light, situated on the ceiling, flashing for the duration of the place trials (the light did not cue the correct goal arm, only trial strategy). Training continued until the rat reached criterion ( 2 consecutive days at $80 \%$ correct for each trial type), after which the rat commenced training on the fixed task. During the fixed task, each rat was given a similar number of place and response trials within a session. However, the place and response trials were interwoven with no more than three consecutive trials of either navigational strategy. Once rats reached criterion they were trained 2-3 times per week until surgery. Rats were given one week to recover from surgery, after which neural recordings commenced. The rats were tested on the fixed task for 1-3 d past criterion. Neural data analyzed was limited to criterion days. All rats were subsequently trained on the novel place task.

Novel place (spatial working memory) and fixed response task (Novel Place Task). Rats were trained to run to a new place goal arm (north, south, east, west) each day during the place trials, while continuing to make a right turn during the response trials (Fig. 1). Daily goal arms were pseudo-randomly assigned. At the start of each training session, the rat was placed at the end of the designated goal arm, while blocked from the rest of the maze, for $\sim 30 \mathrm{~s}$ with the flashing light on and a full cup of chocolate sprinkle reward. After the exposure, the perimeter arms were raised and the rat was guided to the start arm. Each rat was given a similar number of place and response trials within a session. The place and response trials were interwoven with no more than three consecutive trials of either navigational strategy. Previous studies have demonstrated that this task is particularly difficult (Schmidt et al., 2009; Jacobson et al., 2012). Given the difficulty, the place-trial criterion was reduced to 2 consecutive days of $60 \%$ correct (although still above chance, $33 \%$ ), whereas the response criterion was maintained at $80 \%$ correct. Rats were trained to criterion, plus an additional $1-3 \mathrm{~d}$ of criterion days. Learning the "novel place" is considered hippocampal-dependent; Jacobson et al. (2012) showed that hippocampus lesioned rats were impaired on place trials. Neural recordings were taken throughout testing; however, data analysis was limited to learning acquisition (first $3 \mathrm{~d}$ of recording) and criterion (3-5 d of criterion recordings).

Novel response and fixed (original) place task (Novel Response Task). Rats were trained similarly as the novel place task. However, rats were trained to make a new response, a left-hand turn (Fig. 1) during response trials, while continuing to go to the original place arm (east arm) during place trials. As before, each rat was given a similar number of place and response trials within a session. The place and response trials were interwoven with no more than three consecutive trials of either navigational 


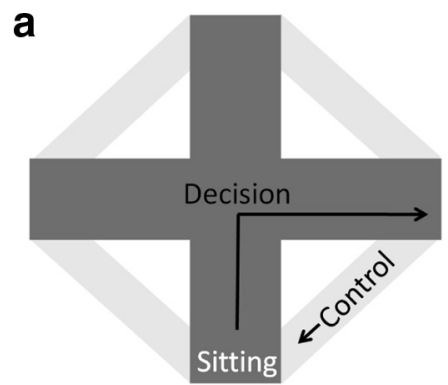

b
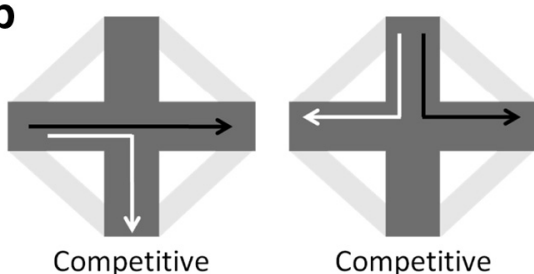

Competitive

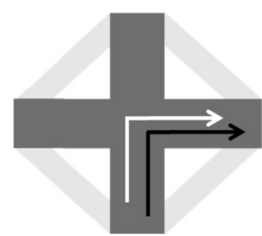

Cooperative

Figure 2. Trial analysis. $\boldsymbol{a}$, Each trial was separated into three segments: waiting at the start arm, running to the goal arm (purported decision-making epoch of the maze) and running to the start arm (control epoch). $\boldsymbol{b}$, Trials were categorized by navigation strategy (place [black arrow] or response [white arrow] trials) and trial difficulty (competitive/cooperative). On a competitive trial place and response strategies indicated different goal locations. On a cooperative trial both place and response strategies indicated the same goal location.

strategy. Training continued until each rat reached criterion ( 2 consecutive days at $80 \%$ correct for both trial types) and 1-3 subsequent criterion days. Learning the novel response is considered hippocampal-independent; Jacobson et al. (2012) showed that hippocampus lesioned rats performed better than control-lesioned rats. Neural recordings were taken throughout testing; however, data analysis was limited to learning acquisition (first $3 \mathrm{~d}$ of recording) and criterion (3-5 d of criterion recordings).

Maze performance analysis. Data collected during 3-5 d of criterion performance ("criterion") on all three tasks were used for analysis. Additionally, the first $3 \mathrm{~d}$ of learning ("acquisition") were used on the novel place task and the novel response task. Each trial was broken into segments: running to the start arm (control epoch), waiting at the start arm, and running to the goal arm (purported decision-making epoch) (Fig. $2 a$ ). The configuration of the plus maze allowed for a trial analysis based on trial difficulty: competitive/cooperative (Schmidt et al., 2009, 2013; Jacobson et al., 2012). On a "cooperative trial" either navigation strategy (place or response) would lead to the correct goal arm. For example, a rat that started from the south arm could use a place strategy, which would lead to the east arm, or a response strategy and make a right turn also ending on the east arm. On a "competitive trial", the two navigation strategies lead to different goal arms (Fig. $2 b$ ).

Surgery. The rats were anesthetized with ketamine/xylazine anesthesia (i.m., $50 \mathrm{mg} / \mathrm{kg}$ ketamine, $1 \mathrm{mg} / \mathrm{kg}$ acepromazine, and $5 \mathrm{mg} / \mathrm{kg}$ xylazine) $4 \mathrm{mg} / \mathrm{kg}$, and placed in a stereotaxic apparatus (ASI Instruments). The scalp was shaved and betadine was applied to the scalp and ophthalmic ointment to the eyes. An incision was made in the scalp and several small anchor screws were fastened to the skull. Two electrode arrays $(50 \mu \mathrm{m}$ tungsten wires; California Fine Wire) were implanted into the ipsilateral dorsal hippocampus (A/P - 3.5/, L/M 2.5, D/V 2.5) and ventral hippocampus (A/P -5.5/, L/M 5.5, D/V 6.0) according to Paxinos and Watson (1986). Four rats were implanted with electrodes in dorsal hippocampus and four rats were implanted with electrodes in both dorsal and ventral hippocampus (Fig. 3a). Electrodes comprised four wires and were spaced evenly along the medial-lateral axis and cut at a slight angle. The electrodes were targeted to CA1. The same electrodes were used for all analyses. Two ground screws were placed over the cerebellum to use as reference. Rats received the analgesic Metacam $1 \mathrm{mg} / \mathrm{kg}$ (oral) after surgery and for the following $2 \mathrm{~d}$. After surgery, the rats were given penicillin $\mathrm{G}$ procaine (i.m.) to prevent infection. The animals were placed in a clean cage with a heating pad until ambulatory, after which they were single housed in clean cages with bedding. The animals were allowed one week to recover before recording.

Recordings. Wide-band electrical activity was recorded $(1-2000 \mathrm{~Hz}$, 3787 samples/s) (Fig. 3b) using Neuralynx Data Acquisition System. Light-emitting diodes attached to the headstage were tracked with an overhead camera (33 samples/s) and monitored with the Neuralynx Video Tracker. Data were selected and analyzed off-line. All data were initially inspected visually (Neuraview, Neuralynx) to remove any segments of bad signal (e.g., due to a loose connection, bumping head). All signal analysis was conducted using custom-written programs in MatLab (Mathworks).

Data were then segmented using Neuralynx Video Tracker File Playback and Event Session Splitter to select specific behavioral epochs. As mentioned, each trial was broken into segments, running to the start arm (control epoch), waiting at the start arm, and running to the goal arm (purported decision-making epoch) (Fig. 2a), and truncated into $1.5 \mathrm{~s}$ segments. Running speed for each trial was calculated as the positional difference between successive tracking samples and then low-pass filtered (cutoff $=0.25 \mathrm{~Hz}$ ) to minimize the contribution of head movements and movement artifacts to the overall speed. Power spectral density estimates were obtained in MatLab using Welch's averaged modified periodogram method (Welch, 1967) (Fig. 3c). Each session was then blocked and power and frequency estimates were obtained for each segment of every trial. Power estimates were obtained for the theta band $(6-10 \mathrm{~Hz})$ and represented as decibels $(\mathrm{dB})$ relative to $1 \mu \mathrm{V}$ (Fig. $3 e, f$ ). Instantaneous frequency was determined by calculating the change in phase divided by the change in time between each sample (Hinman et al., 2011).

Coherence values were taken from segments of each behavioral epoch concatenated into a single continuous string of data (Sabolek et al., 2009; Hinman et al., 2011, 2013; Penley et al., 2012). To accomplish this, a cross fading procedure was applied where the first and last $100 \mathrm{~ms}$ of each data segment was ramped or faded respectively with a smooth B-spline window with continuous second-order derivates (Roark and Escabi, 1999). Adjacent start and end blocks from subsequent segments were then overlapped and morphed by adding the signals overlapping the ramp and fade regions.

Coherence values (Bullock et al., 1990) for each channel pair were computed using the Welch periodogram estimation procedure with a spectral resolution of $\sim 2 \mathrm{~Hz}$. Coherence is a measure of the linear association between two signals as a function of the frequency. The coherence $\left[C_{x y}(\omega)\right]$ between two signals, $x$ and $y$, is equivalent to the crossspectrogram $\left[P_{x y}(\omega)\right]$ magnitude normalized by the averaged power spectrum of the individual signals $\left[P_{x x}(\omega)\right.$ and $\left.P_{y y}(\omega)\right]$. To ensure that that measured coherence values are not due to chance alone, a significance estimation procedure was devised in which the coherence estimate was compared with that of signals with identical magnitude spectrum but with zero phase coherence. For each channel pair, the cumulative distribution of the frequency-dependent coherence values is created by circularly phase shifting one signal in the pair by a random amount, calculating the coherence for the shifted signals, and bootstrapping the procedure 250 times (Efron and Tibshirani, 1993). This procedure guarantees that the signal spectrums are identical but have no linear association, because the phase or time information has been removed. The coherence distribution is used to determine a threshold for each frequency band ( $2 \mathrm{~Hz}$ resolution), below which $95 \%$ of the shifted null hypothesis coherence values fell. Only regions of the nonshuffled signal coherences falling above the $95 \%$ threshold were considered significant (Sabolek et al., 2009; Hinman et al., 2011, 2013; Penley et al., 2012). For each channel pair, the statistically significant area in the theta $(6-10 \mathrm{~Hz})$ band was calculated, and normalized by the frequency range (expressed as average coherence value per $\mathrm{Hz}$ ). Average coherence values were normalized relative to the observed maximum for each frequency range, determined by calculating the significant areas in each frequency range for a channel pair where both elements of the pair are the same channel $\left(C_{x x}^{2}=1.0\right.$ at all frequencies). The resulting normalized coherence value falls between 0 and 1 (Fig. 3d).

Histology. Rats were perfused and examined for verification of electrode locations. Rats were killed in a carbon dioxide chamber and transcardially perfused with $100 \mathrm{ml}$ of saline followed by $400 \mathrm{ml}$ of $4 \%$ fresh paraformaldehyde and $0.2 \%$ glutaraldehyde dissolved in $0.1 \mathrm{M} \mathrm{PB}$. The 

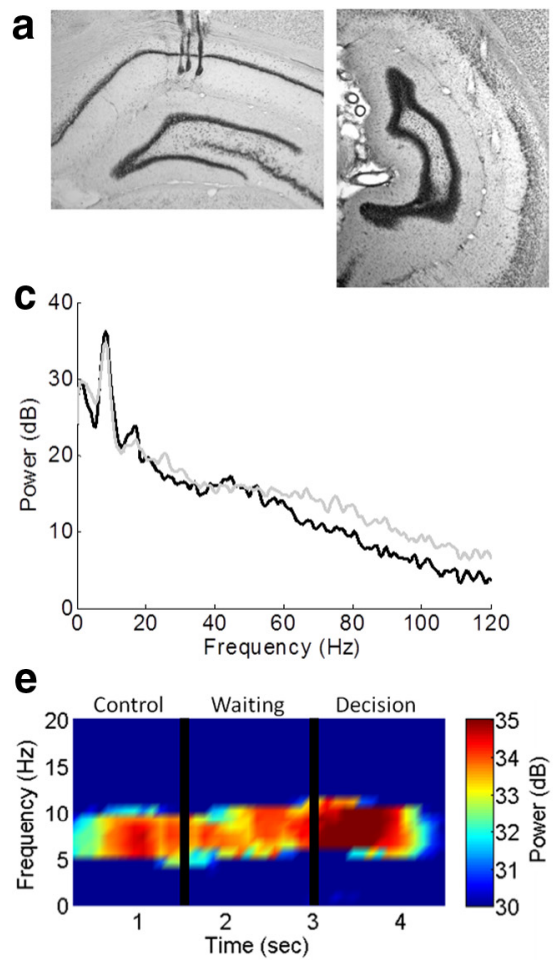

b
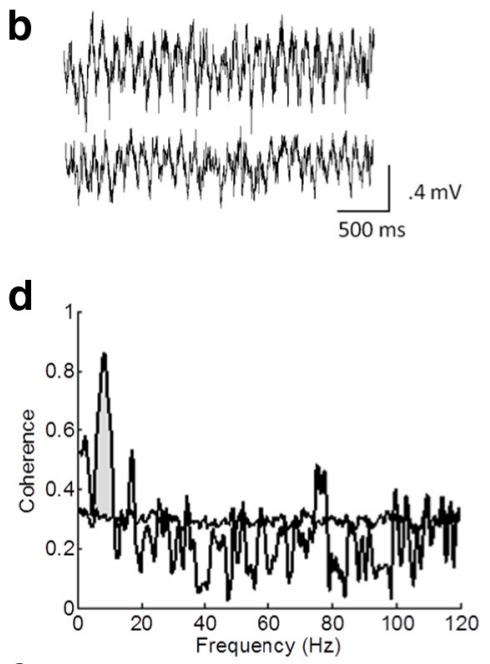

f

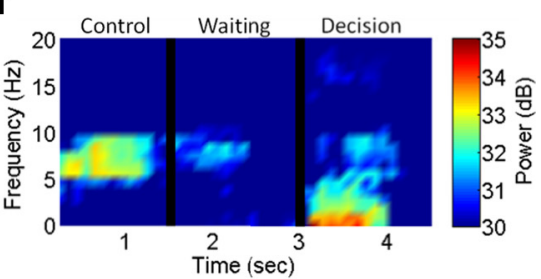

Figure 3. $\quad \boldsymbol{a}$, Example placements of dHipp (left) and vHipp (right) electrodes. $\boldsymbol{b}$, Example trace of dHipp (top) and vHipp (bottom) raw signal. c, Power spectrum density of dHipp (black) and vHipp (gray) electrodes. $\boldsymbol{d}$, Coherence spectrum between dHipp and vHipp electrodes. Normalized coherence was calculated as more than the $95 \%$ of shuffled signals (horizontal line; see Materials and Methods). $\boldsymbol{e}, \boldsymbol{f}$, Examples of power spectrogram of dHipp (e) and vHipp (f) segmented into the control, waiting, and decision epochs.

brains were removed and stored in fixative overnight. The brains were placed in a $30 \%$ sucrose solution for $3 \mathrm{~d}$. The brains were frozen and coronally sliced at $60 \mu \mathrm{m}$ on cryostat and stained with thionin.

Statistics. To examine the relationship between theta power and running speed a correlation (Pearson's $r$ ) was used. A paired $t$ test was used to assess within structure differences between running speed, theta power, frequency, and coherence during decision-making and the control epoch. All trial types (place and response trials) were collapsed for speed analyses, correlations, and changes in theta frequency, power, and coherence. A two-sampled $t$ test was used to assess between structure differences. Last, to assess the effects of different cognitive variable of the task a linear regression was fit with maze location (control vs decision epochs) and running speed as explanatory variables. Subsequent $\beta$ values were compared with 0 with a paired $t$ test. There were some effects of task manipulations as the animals were preparing to initiate a response (sitting epoch). These data were separate by navigation strategy (place and response), trial difficulty (competitive and cooperative) or trial accuracy (correct and errors).

\section{Results}

Analyses were made from electrodes located in CA1 layer stratum radiatum. One rat had a placement in the molecular layer of the dorsal dentate gyrus and a separate rat in the ventral dentate gyrus; given that no differences were found, the data were collapsed. Recordings were made from all animals on all paradigms. However, the signal degraded in three of the animals on the novel response task (last task) and their data were not used.

\section{Comparison of trial segments and tasks}

The animals performed three tasks that differed in the amount of hippocampal dependence (Jacobson et al., 2012), most notably that lesions to the hippocampus affected performance during place, but not response trials. The fixed place and response task
(Fixed Task) included hippocampaldependent spatial reference memory (east arm) and hippocampal-independent (right turn) trials. The novel place and fixed response task (Novel Place) included hippocampal-dependent spatial working memory (new goal arm each day) and hippocampal-independent (right turn) trials. The novel response and fixed place task (Novel Response) included hippocampal-dependent spatial reference memory (again the east goal arm) and hippocampal-independent learning (novel response, left turn) trials. To dissociate the effects of running speed on theta power, all three tasks encompassed two segments of running (Fig. 2a): the first when choosing the goal arm (decision epoch) and the second after receiving the reward and running to the next start position (control epoch). The decision epoch presumably involves planning and executing the correct trajectory for a given trial; the control epoch could include processing the results of the previous trial in addition to following the only path available to the next start position.

\section{Theta frequency}

Previous studies have shown changes in theta frequency with experience and environmental novelty independent of running speed (Jeewajee et al., 2008). Therefore, we first examined differences in peak theta frequency along the septotemporal axis and the effects of cognitive demands.

\section{Fixed task}

There was a trend for a higher peak theta frequency in the dHipp than vHipp $\left(t_{(47)}=1.99, p=0.052\right)$ (Fig. $\left.4 a\right)$. Additionally, peak theta frequency increased during the decision (compared with the control) epoch in both the dHipp $\left(t_{(30)}=\right.$ $5.11, p<0.001)$ and vHipp $\left(t_{(17)}=3.11, p<0.01\right)$. This effect was similar between the dHipp and vHipp $\left(t_{(47)}=1.18, p>0.10\right)$ (Fig. 4a). A linear regression was fit for theta frequency with maze location (control/decision) and running speed as explanatory variables. The regression revealed that both maze location $(\beta=$ $0.232, p<0.05)$ and running speed $(\beta=0.465, p<0.001)$ modulated dHipp theta frequency. In contrast, though maze location had a modulatory effect in the vHipp $(\beta=0.319, p<$ $0.05)$, there was only a trend for speed $(\beta=0.297, p=0.065)$.

Novel place task

Peak theta frequency was greater in the dHipp than the vHipp $\left(t_{(85)}=4.12, p<0.001\right)$ (Fig. $\left.4 b\right)$. Peak theta frequency increased during the decision epoch in the dHipp $\left(t_{(55)}=8.68, p<0.001\right)$ and a trend was seen in the vHipp $\left(t_{(30)}=2.01, p=0.053\right)$. The dHipp had a greater change in peak frequency during the decision epoch than the vHipp $\left(t_{(85)}=2.95, p<0.01\right)$ (Fig. $\left.4 b\right)$. The regression analysis suggest, again, that both maze location $(\beta=$ $0.402, p<0.001)$ and running speed $(\beta=0.355, p<0.001)$ modulated dHipp theta frequency. In contrast to the dHipp and the fixed task, speed modulated frequency in the vHipp $(\beta=$ $0.317, p<0.05)$, whereas, the maze location $\operatorname{did} \operatorname{not}(\beta=0.202$, $p=0.099)$. 


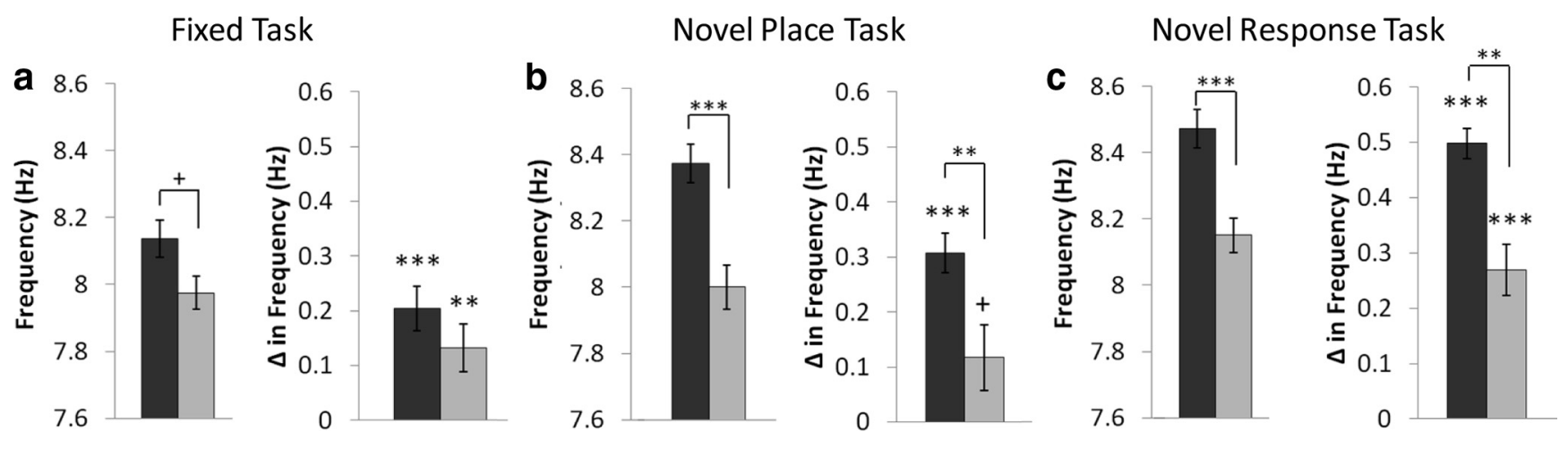

Figure 4. Dissociations in theta frequency. $\boldsymbol{a}-\boldsymbol{c}$, Peak theta frequency (left) and change in theta frequency during the decision versus the control epoch (right) on the fixed task (a), novel place task (b), and novel response task (c). Peak theta frequency was greater in the dHipp than the vHipp. Peak theta frequency was higher during the decision epoch in both the dHipp and the vHipp, this effect was greater in the dHipp. ${ }^{+} p=0.052,{ }^{* *} p<0.01,{ }^{* * *} p<0.001$.

Novel response task

Consistent with the previous two tasks, peak theta frequency was greater in the dHipp than the vHipp $\left(t_{(54)}=4.14, p<0.001\right)$ (Fig. 4c). Peak theta frequency increased during the decision epoch in both the dHipp $\left(t_{(29)}=18.25, p<0.001\right)$ and the vHipp $\left(t_{(25)}=5.88, p<0.001\right)$, and the change in frequency during the decision epoch was greater in the dHipp $\left(t_{(54)}=4.44\right.$, $p<0.01$ ) (Fig. $4 c$ ). The regression analysis revealed that both maze location $(\beta=$ $0.609, p<0.001)$ and running speed $(\beta=$ $0.459, p<0.001)$ modulated dHipp theta frequency. Both maze location $(\beta=0.439$, $p<0.001)$ and running speed $(\beta=0.479$, $p<0.001$ ) affected vHipp theta frequency, as well.

We found consistent changes in theta frequency regardless of whether the running speeds were similar or different between behavioral epochs across tasks (see below). These changes were seen independent of new learning (i.e., even in the fixed task), suggesting that the effects were the result of the cognitive demands of the task and not new learning or novelty. Similar to Jeewajee et al. (2008), we found that the change in dHipp theta frequency could be dissociated from running speed. The cognitive demands of the task exerted a greater affect on changes in dHipp frequency than running speed; though vHipp theta frequency proved to be more variable.

\section{Speed modulation of dorsal and ventral theta}

Theta oscillations are modulated by both volitional movement and mnemonic processes (Raghavachari et al., 2001; Kelemen et al., 2005; Shin, 2011; Voss et al., 2011; Kaplan et al., 2012). Theta power is positively correlated with running speed (Vanderwolf, 1969; Steward and Vanderwolf, 1987; Hinman et al., 2011). Similarly, dHipp theta power has been shown to be modulated at the choice point on a hippocampal-dependent spatial alternation task (Montgomery et al., 2009). To dissociate the effects of volitional movement and cognitive demands on theta power, the correlation values between running speed and theta power were examined during the decision and control epochs of the maze for each training session (Fig. 5).
Fixed task

In accord with previous studies, theta power and running speed were correlated. This was seen in both the dHipp and the vHipp during the control (dHipp $t_{(30)}=3.16, p<0.01$; vHipp $t_{(17)}=$ $3.91, p<0.01)$ and decision epoch ( $\mathrm{dHipp} t_{(30)}=2.49, p<0.05$; vHipp $t_{(17)}=5.48, p<0.001$ ) (Fig. 5b). Examining the correlation values between the control and decision epochs revealed no differences in the vHipp $\left(t_{(17)}=-1.12, p>0.10\right)$. However, there was a trend for a reduced correlation in the $\operatorname{dHipp}\left(t_{(30)}=\right.$ $1.88, p=0.07)$, despite the fact that rats ran faster during the decision epoch $\left(t_{(30)}=3.65, p<0.001\right)$ (Fig. $\left.5 a, b\right)$. The results held true when the correlation values were transformed with a Fishers $r$-to- $z$ transformation (data not shown).

\section{Novel place task}

Running speed and theta power were correlated in both the dHipp $\left(t_{(55)}=5.04, p<0.001\right)$ and vHipp $\left(t_{(30)}=5.73, p<\right.$ $0.001)$ during the control epoch. This was also the case in the vHipp $\left(t_{(30)}=9.27, p<0.001\right)$, but not dHipp $\left(t_{(55)}=1.07, p>\right.$ 0.10 ), during the decision epoch (Fig. $5 d$ ). Examining the correlation values between the control and decision epochs revealed that the relationship between dHipp theta power and running 
speed was significantly reduced during the decision epoch $\left(t_{(55)}=\right.$ 2.63, $p<0.05)$. However, no differences were seen between the control and decision epochs in vHipp theta $\left(t_{(30)}=-0.96, p>\right.$ $0.10)$. The results held true with the Fishers $r$-to- $z$ transformation (data not shown). This dissociation was seen despite no differences in running speed between the decision and control epoch $\left(t_{(55)}=0.30, p>0.10\right)$ (Fig. $5 c$ ). The data suggest that the relationship between running speed and hippocampal theta power "uncoupled" during the decision-making epoch, but this effect was specific to the dHipp.

\section{Novel response task}

In accord with the previous two tasks, running speed and theta power were correlated in both the dHipp $\left(t_{(29)}=2.19, p<0.05\right)$ and vHipp $\left(t_{(25)}=4.57, p<0.001\right)$ during the control epoch. This was also seen in the vHipp $\left(t_{(25)}=9.94, p<0.001\right)$ during the decision epoch (Fig. $5 f$ ), but not the dHipp $\left(t_{(29)}=-0.79\right.$, $p>0.05)$. Similar to the novel place task, the relationship between running speed and theta power was significantly reduced during the decision epoch in the dHipp $\left(t_{(29)}=3.38, p<\right.$ 0.01 ). In contrast, the relationship between running speed and vHipp theta power was greater during the decision epoch $\left(t_{(25)}=\right.$ $-1.87, p<0.05)$. The results held true with the Fishers $r$-to- $z$ transformation (data not shown). Again, these effects were seen despite no differences in running speed $\left(t_{(29)}=1.73, p>0.09\right)$ (Fig. 5e). Similar to the novel place task, the relationship between running speed and theta power uncoupled in the dHipp during decision-making.

Even though theta power is correlated with the animal's running speed, it is also influenced by other factors. The current results revealed that the influence of mnemonic processes on dHipp theta power can be dissociated from volitional movement, an effect that was relatively consistent across tasks. Processes related to decision-making/planning and/or executing the correct trajectory contributed to an equal or greater degree as speed to theta in the dHipp.

\section{Increased theta power during decision-making}

Previous studies have shown increased dHipp theta power during decision-making (Montgomery et al., 2009). Given the reported functional dissociations along the septotemporal axis (Fanselow and Dong, 2010), we examined whether this relationship was uniform between the dorsal and ventral hippocampus.

\section{Fixed task}

Theta power increased within the dHipp during the decision, compared with the control, epoch $\left(t_{(30)}=3.12, p<0.01\right)$; in contrast, vHipp theta power decreased during the decision epoch $\left(t_{(17)}=-2.67, p<0.05\right.$ ) (Fig. 6a). The change in theta power during the decision epoch was greater in the dHipp than vHipp $\left(t_{(47)}=3.90, p<0.001\right)$. This was a consistent effect seen across rats and days. The theta power ratio (decision epoch theta power/ control epoch theta power) was plotted against the running speed ratio (decision epoch running speed/control epoch running speed) (Fig. 6b). dHipp theta power consistently increased during the decision epoch (most points above the 1.0 horizontal axis), even when animals ran at the same speed or slower than the control epoch (points distributed on the left of the 1.0 vertical axis). In contrast, vHipp theta power decreased during the decision epoch regardless of the change in speed (most points below the 1.0 horizontal axis).

To further examine whether volitional movement can be dissociated from the cognitive demands of the task on theta power, a linear regression was fit with running speed and maze locations/ segment (control vs decision epoch) as explanatory variables (Fig. $6 c)$. Both running speed $\left(\beta=0.11 ; t_{(30)}=3.68, p<0.001\right)$ and maze segment $\left(\beta=0.19 ; t_{(30)}=5.30, p<0.001\right)$ modulated theta power in the dHipp. However, there was a trend for maze segment to have a greater effect than running speed $\left(t_{(30)}=1.94\right.$, $p=0.06)$. Though speed modulated vHipp theta power $(\beta=$ $\left.0.24 ; t_{(17)}=7.70, p<0.001\right)$, maze segment had a reverse effect $\left(\beta=-0.12 ; t_{(17)}=-2.99, p<0.01\right)$. In contrast to the dHipp, running speed had a greater effect than maze segment on vHipp theta power $\left(t_{(17)}=-9.0, p<0.001\right)$.

\section{Novel place task}

Similar to the fixed task, dHipp theta power increased during the decision epoch $\left(t_{(55)}=9.37, p<0.001\right)$ (Fig. $\left.6 d\right)$, despite no differences in running speed (see above). Interestingly, this increase was greater for the novel place task than the fixed task $\left(t_{(85)}=\right.$ $3.34, p<0.01)$. In contrast, there was a trend for decreased vHipp theta power during the decision epoch $\left(t_{(30)}=-1.95, p=0.06\right)$ (Fig. $6 d$ ). When compared, the change in theta power during the decision epoch was greater in the dHipp than the vHipp $\left(t_{(85)}=\right.$ $7.3, p<0.001)$. Again, this was a consistent effect across animals and days (Fig. 6e), despite no differences in running speed (points evenly distributed across the 1.0 vertical axis).

A linear regression was fit with running speed and maze locations as explanatory variables (Fig. $6 f$ ). Though both running speed $\left(\beta=0.10 ; t_{(55)}=5.91, p<0.001\right)$ and maze location modulated dHipp theta power $\left(\beta=0.31 ; t_{(55)}=13.11, p<\right.$ $0.001)$, maze location had a greater effect $\left(t_{(55)}=7.18, p<0.001\right)$. The lower running speed $\beta$ values in the dHipp could similarly reflect the uncoupling between running speed and theta power during decision-making. Again, speed modulated theta power in the vHipp $\left(\beta=0.24 ; t_{(30)}=9.19, p<0.001\right)$, but maze segment had the opposite effect $\left(\beta=-0.10 ; t_{(30)}=-2.16, p<0.05\right)$. In contrast to the dHipp, running speed had a greater effect than maze segment on vHipp theta power $\left(t_{(30)}=-7.82, p<0.001\right)$.

\section{Novel response task}

Similar to the previous two tasks, dHipp theta power increased during the decision epoch $\left(t_{(29)}=7.71, p<0.001\right.$ ) (Fig. $6 g$ ), despite similar running speeds (see above). This increase was greater for the novel response task than the fixed task $\left(t_{(59)}=\right.$ 3.23, $p<0.01)$, but did not differ from the novel place task $\left(t_{(84)}=-0.15, p>0.10\right)$. Theta power decreased in the vHipp during the decision epoch $\left(t_{(25)}=-5.22, p<0.001\right)$ (Fig. $6 g$ ). The change in theta power during the decision epoch was greater in the dHipp than vHipp $\left(t_{(54)}=9.1, p<0.001\right)$. Again, change in theta power was consistent across rats and days (Fig. $6 h$ ).

A linear regression was fit with running speed and maze locations as explanatory variables (Fig. 6i). Running speed did not modulate dHipp theta power $\left(\beta=0.04 ; t_{(29)}=0.92, p>0.10\right)$ though maze segment did $\left(\beta=0.33 ; t_{(29)}=9.93, p<0.001\right)$. As expected, maze location had a greater effect than running speed on theta power $\left(t_{(29)}=6.17, p<0.001\right)$. Similar to the novel place task, running speed modulated vHipp theta power $\left(\beta=0.21 ; t_{(25)}=\right.$ 9.54, $p<0.001)$, whereas maze had the opposite effect $(\beta=$ $\left.-0.17 ; t_{(25)}=-5.3, p<0.001\right)$. Running speed had a greater effect on vHipp theta power than maze location $\left(t_{(25)}=-10.46\right.$, $p<0.001)$. Again, the lower $\beta$ values in the dHipp could reflect the dissociation between running speed and theta power during decision-making.

The results demonstrated that dHipp and vHipp theta power were consistently modulated, albeit in an opposite manner, 

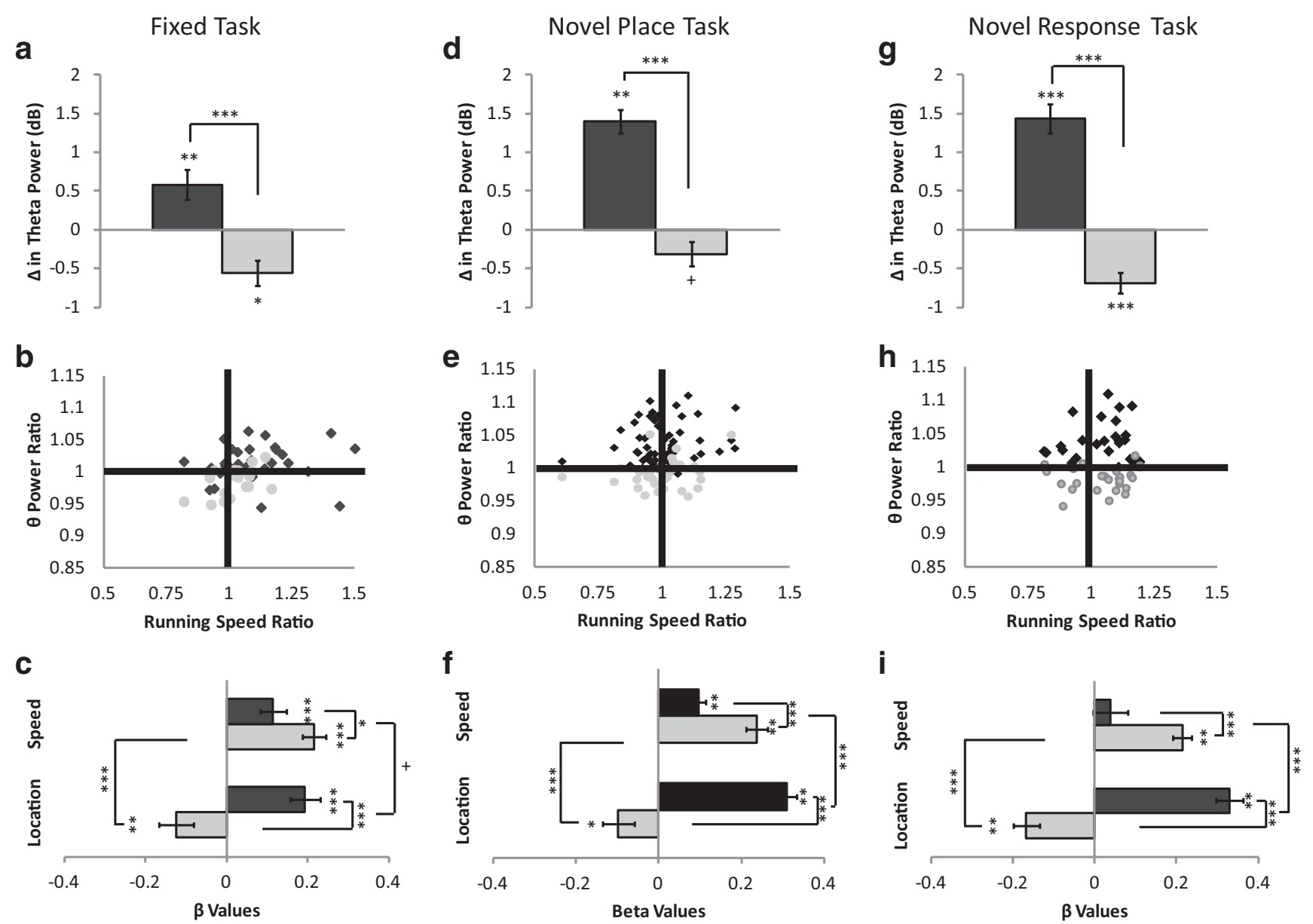

Figure 6. Dissociation between dHipp and vHipp theta power during decision-making. dHipp theta power increased during the decision epoch of the maze. In contrast, theta power decreased in the vHipp during the decision epoch. $\boldsymbol{a}, \boldsymbol{d}, \boldsymbol{g}$, These effects were consistently seen on the fixed task (a), novel place task (d), and novel response task ( $\boldsymbol{g})$. $\boldsymbol{b}, \boldsymbol{e}, \boldsymbol{h}$, For each day of each rat the theta power ratio (decision epoch theta power/control epoch theta power) was plotted against the running speed ratio (decision epoch running speed/control epoch running speed) for the fixed task (b), novel place task $(\boldsymbol{e})$, and novel response task $(\boldsymbol{h})$. The $\beta$ values for maze segment occupied (location) and running speed are plotted for both the dHipp and the vHipp. Both maze location (decision vs control epoch) and running speed modulated theta power in the dHipp, though maze location consistently had a greater modulating effect. This was also the case in the vHipp, though maze location had the opposite effect. $\boldsymbol{c}, \boldsymbol{f}, \boldsymbol{i}$, These effects were consistently seen on the fixed task $(\boldsymbol{c})$, novel place task $(\boldsymbol{f})$, novel response task $(\boldsymbol{i})$. ${ }^{+} p=0.06,{ }^{*} p<0.05$, ${ }^{* *} p<0.01,{ }^{* * *} p<0.001$.

across tasks. Montgomery et al. (2009) has previously shown increased theta power during the decision epoch in rats trained on a spatial alternation task. In contrast, this study did not require the rats to retrieve the previous trial for successful performance, suggesting that the changes in theta power reflected global decision-making processes that could be dissociated from trial by trial encoding/retrieval processes. Interestingly, theta power was greater during decision-making on the tasks with new learning (novel place and novel response) than the well trained task (fixed task). Whether this was an effect of learning or task difficulty is unclear. However, the different hippocampal dependence of the three tasks suggests that the changes in theta power did not strictly reflect hippocampal-dependent information processes.

\section{Theta coherence during the decision epoch}

Theta coherence within the dHipp increases during decisionmaking (Montgomery et al., 2009). We examined whether this relationship was similar along the septotemporal axis. Significant normalized theta coherence was calculated as the area within a specific frequency band that fell above the $95 \%$ confidence interval (see Materials and Methods). Theta coherence was measured between electrode pairs within the dHipp, within the vHipp, and between the dHipp and the vHipp.

\section{Fixed task}

Theta coherence was greater within dHipp electrode pairs during the decision epoch than the control epoch $\left(t_{(30)}=2.27, p<0.05\right)$ (Fig. 7a). However, this effect was not seen within vHipp electrode pairs $\left(t_{(17)}=1.25, p>0.10\right)$, nor between dHipp and vHipp electrode pairs $\left(t_{(17)}=0.93, p>0.10\right)$.

\section{Novel place task}

Unlike the fixed task, where theta coherence increased solely in the dHipp, during the novel place task, theta coherence increased during the decision epoch within dHipp electrode pairs $\left(t_{(52)}=\right.$ $4.89, p<0.001)$, within vHipp electrode pairs $\left(t_{(30)}=2.98, p<\right.$ $0.01)$, and between dHipp and vHipp electrode pairs $\left(t_{(30)}=2.31\right.$, $p<0.05)$ (Fig. 7b).

Novel response task

Similar to the fixed task, theta coherence increased only within dHipp electrode pairs $\left(t_{(29)}=2.95, p<0.01\right)$, with a trend for an increase within vHipp electrode pairs $\left(t_{(25)}=1.97, p=0.06\right)$. 

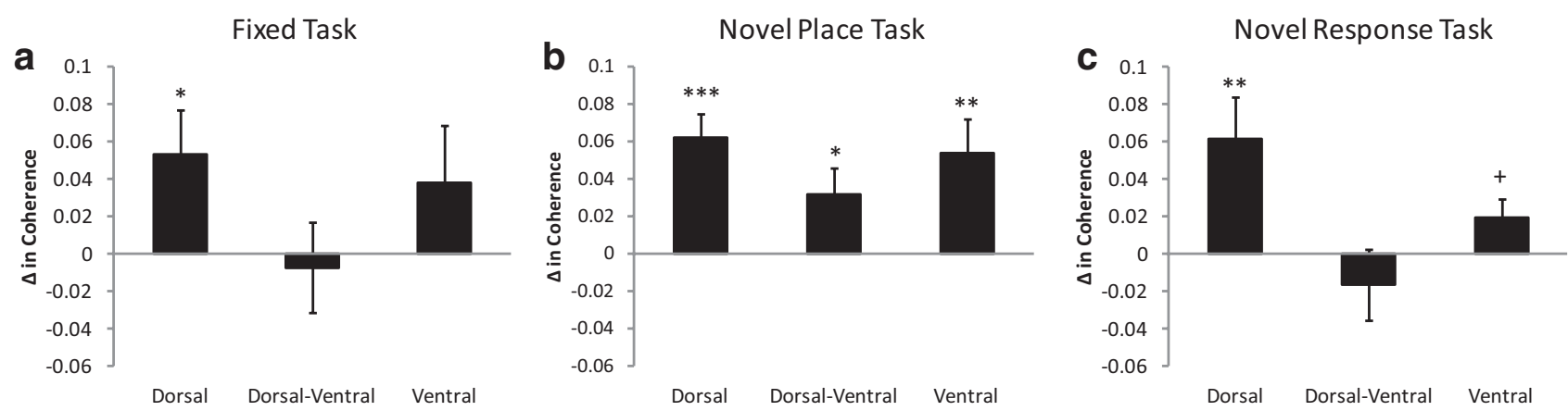

Figure 7. Coherence along the septotemporal axis during the control and decision epochs. Significant normalized coherence was measured within the dHipp and the vHipp, as well as between the dHipp and the vHipp. $\boldsymbol{a}$, Fixed task: normalized coherence was greater during the decision epoch within the dHipp (dorsal), no differences were seen within the vHipp (ventral), nor between the dHipp and vHipp (dorsal-ventral). $\boldsymbol{b}$, Novel place task: normalized theta coherence increased within the dHipp, within the vHipp, as well as between the dHipp and the vHlipp during the decision epoch. $c$, Novel response task: again, normalized theta coherence increased within the dHipp, despite no differences in normalized coherence within the vHipp or between the dHipp and the vHipp. ${ }^{+} p=0.06,{ }^{*} p<0.05,{ }^{* *} p<0.01,{ }^{* * *} p<0.001$.

However, no differences in theta coherence were seen between dHipp and vHipp electrode pairs $\left(t_{(25)}=0.84, p>0.10\right)($ Fig. $7 c)$.

\section{Effect of learning}

In all three tasks, performance improved over the course of the recording session (over trials), even at asymptotic performance. This improvement occurred despite a presumed decrease in motivation as the animal satiated and tired. The novel place task and the novel response task were taught after electrode implantation, permitting analysis during learning (acquisition) and at asymptotic performance (criterion) (see Materials and Methods). Given that theta power is modulated during learning (Masuoka et al., 2006; Tort et al., 2009), we examined changes in theta power within (first 10 trials vs the last 10 trials) and across recording sessions.

\section{Fixed task}

Though trained extensively and at asymptotic levels, performance varied within the daily recording session. Rats were more accurate on the last 10 trials of the recording session than the first 10 trials $\left(t_{(30)}=6.04, p<0.001\right)$ (Fig. $\left.8 a\right)$, despite no differences in running speed within the recording session (first 10 vs last 10 trials) $\left(t_{(30)}=0.74, p>0.10\right)$. In contrast, running speed was greater during the decision epoch on the first 10 trials $t_{(30)}=$ 2.61, $p<0.05$ ) and a trend for an increase in the last 10 trials $\left(t_{(30)}=1.94, p=0.06\right)$ (Fig. $\left.8 b\right)$. dHipp theta power increased during the decision epoch in both the first 10 trials $\left(t_{(30)}=5.16\right.$, $p<0.001)$ and last 10 trials of the recording session $\left(t_{(30)}=2.48\right.$, $p<0.05$ ) (Fig. 8c). The change in theta power (increase) was similar across the first and last 10 trials $\left(t_{(30)}=1.40, p>0.10\right)$.

In the vHipp, theta power was similar between the control and decision epochs during the first 10 trials $\left(t_{(17)}=0.24, p>0.10\right)$, however theta power decreased during the last 10 trials $\left(t_{(17)}=\right.$ $-3.96, p<0.01$ ) (Fig. $8 d$ ). Thus, the increase in accuracy over trials was reflected by a decrease in decision epoch theta power in the vHipp $\left(t_{(17)}=-2.50, p<0.05\right)$.

\section{Novel place task}

Performance improved throughout the daily recording session whether at acquisition $\left(t_{(18)}=5.67, p<0.001\right)$ (Fig. $8 e$ ) or criterion $\left(t_{(35)}=5.76, p<0.001\right)$ (Fig. $8 i$ ). At acquisition, dHipp theta power increased during the decision epoch for both the first 10 $\left(t_{(18)}=5.32, p<0.001\right)$ and last 10 trials $\left(t_{(18)}=3.29, p<0.01\right)$ (Fig. $8 g$ ). These effects were seen despite no differences in running speed between the decision and control epoch $\left(t_{(18)}=-0.45, p>0.10\right)$
(Fig. $8 f$ ) or within the recording session $\left(t_{(18)}=0.38, p>0.10\right)$. This change in theta power during the decision epoch was greater for the first 10 trials $\left(t_{(18)}=3.34, p<0.01\right)$, when the animal made more errors. Similar results were seen at criterion, dHipp theta power increased during the first $10\left(t_{(35)}=7.17, p<0.001\right)$ and last 10 trials $\left(t_{(35)}=4.45, p<0.001\right)$ (Fig. $8 k$ ) despite no differences in running speed between the decision and control epochs (first 10, $t_{(35)}=1.75, p=0.09$; last $\left.10, t_{(35)}=1.15, p>0.10\right)$ (Fig. $8 j$ ) or within the recording session $\left(t_{(35)}=1.45, p>0.10\right)$. Again, the increase in dHipp theta power was greater during the first 10 trials $\left(t_{(35)}=4.55, p<0.001\right)$ when the animal made more errors.

Theta power decreased in the vHipp during the decision epoch in the fixed task, a well learned task. This was notably seen during the last 10 trials. A similar pattern was seen in the novel place task once it was well learned (i.e., at criterion). At acquisition, no differences in vHipp theta power were found between the control and decision epochs during both the first and last 10 trials (first $10, t_{(10)}=0.01, p>0.10$; last $10, t_{(10)}=1.52, p>0.10$ ) (Fig. $8 h)$. Once at criterion, the contrast between the first and last 10 trials became apparent with a decrease in decision epoch theta power found only on the last 10 trials (first $10, t_{(19)}=0.99, p>$ 0.10 ; last $10, t_{(19)}=4.56, p<0.001$ ) (Fig. $8 i$ ). A direct comparison showed that vHipp theta power decreased during the last 10 trials compared with the first $10\left(t_{(19)}=4.85, p<0.001\right)$.

The increase in dHipp theta power during the decision epoch was greatest when the rat first learned the task and early within the daily sessions when the new goal location must be learned. As performance increased (both within and across days), there was less of an increase in theta power during the decision epoch in the dHipp. The opposite dynamic was seen with regard to theta power in the vHipp.

\section{Novel response task}

Rats were more accurate during the last 10 trials of the day at acquisition (trend) $\left(t_{(12)}=2.08, p=0.06\right)$ (Fig. $8 \mathrm{~m}$ ) and criterion $\left(t_{(16)}=4.01, p=0.001\right)$ (Fig. 8q). At acquisition, theta power was greater during the decision epoch in both the first $10\left(t_{(12)}=6.99\right.$, $p<0.001)$ and last 10 trials $\left(t_{(12)}=2.96, p<0.05\right)$ (Fig. 8o). Interestingly, the change in theta power was stronger when the rats were first learning the task (first 10 vs last $10, t_{(12)}=3.75, p<$ $0.01)$ despite no differences in running speed within the recording session $\left(t_{(12)}=1.89, p=0.083\right)$. Similarly, no differences in running speed were seen between the decision and control epoch for the first $10\left(t_{(12)}=-0.12, p>0.10\right)$ and last 10 trials $\left(t_{(12)}=\right.$ 
Fixed Task
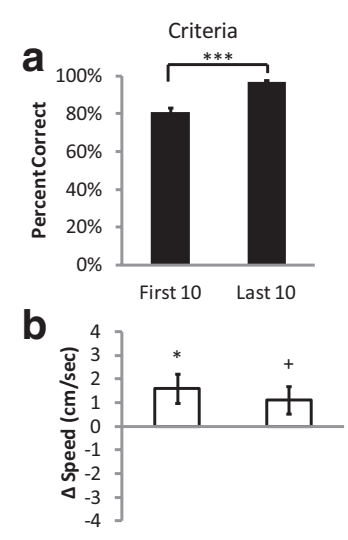

First $10 \quad$ Last 10
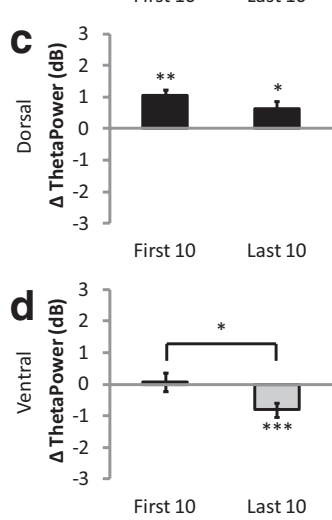
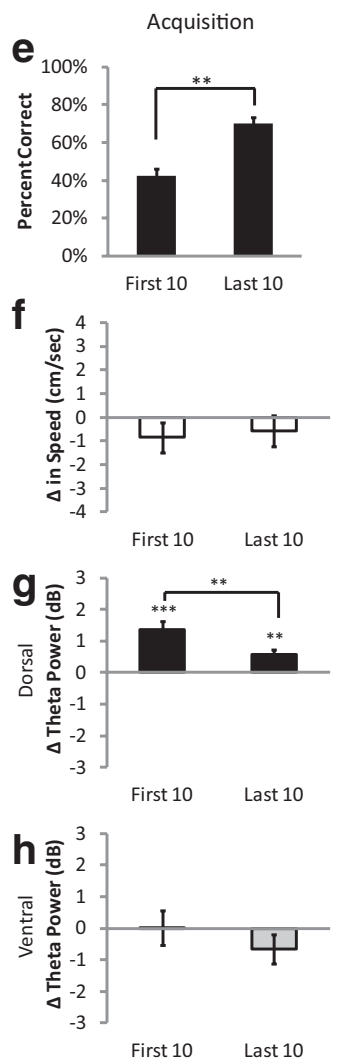

Novel Place Task
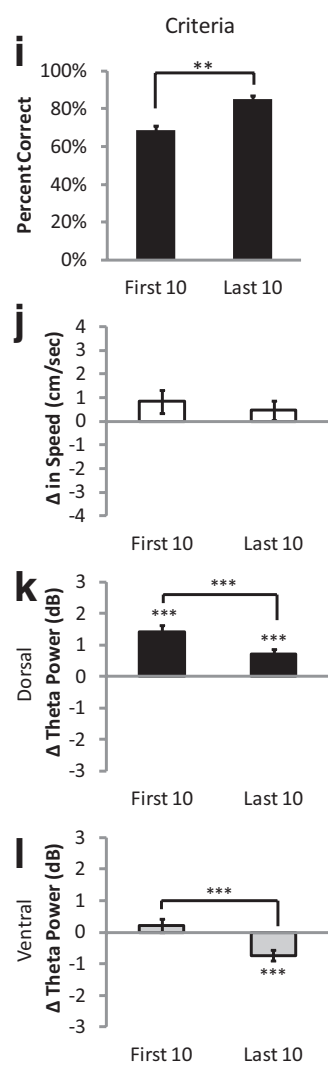
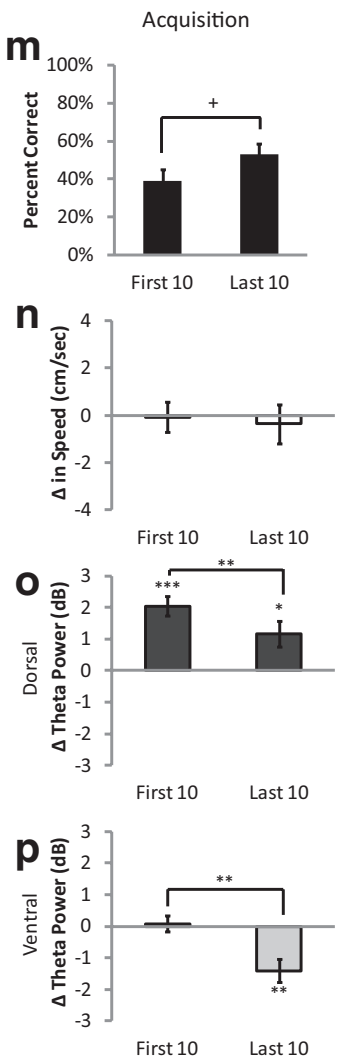
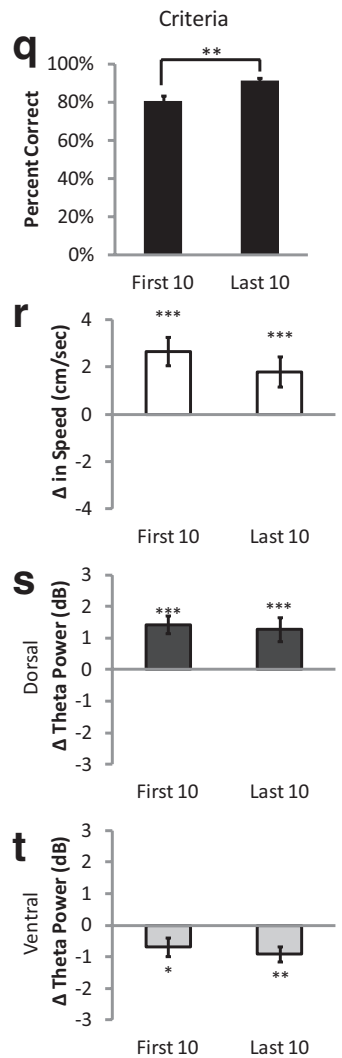

Figure 8. Theta power was modulated with learning, both within and across training days. $\boldsymbol{a}, \boldsymbol{e}, \boldsymbol{i}, \boldsymbol{m}, \boldsymbol{q}$, Percentage correct performance for the first 10 trials and last 10 trials of the fixed task ( $\boldsymbol{a}$ ), novel place task $(\boldsymbol{e}, \boldsymbol{i})$, and novel response task $(\boldsymbol{m}, \boldsymbol{q})$ during acquisition and criterion (see Materials and Methods). Note that daily performance improves during learning acquisitions and asymptotic performance. $\boldsymbol{b}, \boldsymbol{f}, \boldsymbol{j}, \boldsymbol{n}, \boldsymbol{r}$, Change in running speed during the decision epoch on the fixed task $(\boldsymbol{b})$, novel place task $(\boldsymbol{f}, \boldsymbol{j})$, and novel response task $(\boldsymbol{n}, \boldsymbol{r})$. $\boldsymbol{c}, \boldsymbol{g}, \boldsymbol{k}, \boldsymbol{0}, \boldsymbol{s}, \boldsymbol{C}$ (hange in $\mathrm{dHipp}$ theta power during the decision epoch on the first 10 trials and last 10 trials of the training session on the fixed task (c), novel place task $(\boldsymbol{g}, \boldsymbol{k})$, and novel response task $(\boldsymbol{o}, \boldsymbol{s})$. $\boldsymbol{d}, \boldsymbol{h}, \boldsymbol{I}, \boldsymbol{p}, \boldsymbol{t}$, Change in vHipp theta power during the decision epoch on the first 10 trials than the last 10 trials of the training session on the fixed task $(\boldsymbol{d})$, novel place task $(\boldsymbol{h}, \boldsymbol{I})$, and novel response task $(\boldsymbol{p}, \boldsymbol{t})$. ${ }^{+} p=0.06,{ }^{*} p<0.05,{ }^{* *} p<$ $0.01,{ }^{* * *} p<0.001$.

$-0.44, p>0.10$ ) (Fig. $8 n$ ). Similar results were seen at criterion, theta power increased in the decision versus the control epoch during the first $10\left(t_{(16)}=5.24, p<0.001\right)$ and the last 10 trials $\left(t_{(16)}=3.50, p<0.01\right)$ (Fig. 8s), though there was an increase in running speed (first 10, $t_{(16)}=4.49, p<0.001$; last $10, t_{(16)}=2.89$, $p<0.05$ ) (Fig. $8 r$ ). In contrast to theta power changes at acquisition, no differences were seen in theta power between the first and last 10 trials $\left(t_{(16)}=0.39, p>0.10\right)$, despite that fact that rats ran slower throughout the recording session $\left(t_{(16)}=4.5, p<0.001\right)$.

As seen in the previous paradigms, the decision epoch was characterized by a decrease in vHipp theta power. At acquisition, the decrease in decision epoch theta power was found only on the last 10 trials (first $10, t_{(10)}=-0.31, p>0.10$; last $10, t_{(10)}=$ $-4.05, p<0.01$ ) (Fig. 8p). At criterion, theta power decreased during the decision epoch in both the first and last 10 trials (first $10, t_{(14)}=-11.28, p<0.001$; last $\left.10, t_{(14)}=-4.93, p<0.001\right)$ (Fig. $8 t$ ). This effect was greater when the rat was just learning the task (first 10 vs last $10, t_{(19)}=4.85, p<0.001$ ).

Across all three tasks animals tended to improve their performance throughout the session with no systematic change in relative running speed between the control and decision epochs. Overall, dHipp theta increased, especially in the first trials of the maze session; conversely, vHipp theta power decreased mostly during the later trials on the maze.

Interestingly, the increased dHipp theta power seen during the decision epoch was relatively stable within session when the rats were at asymptotic performance (criterion) on the fixed task and novel response task. In contrast, dHipp theta power was greatest early in the training session on paradigms that required new learning (acquisition on the novel place task and novel response task) and even when the rats were at asymptotic performance but had to learn a novel place arm every day (novel place task).

\section{Minimal effects of task difficulty, error trials, and place strategies on theta power}

To determine the effects of different task demands we compared theta power across trial difficulty (competitive vs cooperative trials), accuracy (error vs correct trials), and navigation strategy (place vs response). We assessed the different cognitive components of the task during the nonambulatory "waiting" portion of the maze which occurred after the rat had been cued to the correct strategy, but before the rat initiated the decision run (Fig. 2a).

\section{Trial difficulty}

Trials were qualified as competitive or cooperative (Fig. 2b). When starting from the north or west arms, place and response strategies indicated different goal arms (competitive trials). Whereas, when starting from the south arm, both place and response strategies indicated the same goal arm (cooperative trials). Competitive trials resulted in more errors when learning the task (novel place task: competitive $19.5 \pm 1.2$, cooperative $1.7 \pm 0.3$ 
mean errors \pm SEM, $t_{19}=14.65, p<0.001$; novel response task: competitive $20 \pm 1.5$, cooperative $9.5 \pm 1.5$, mean errors \pm SEM, $\left.t_{12}=7.85, p<0.001\right)$. Even when at asymptotic performance, competitive trials resulted in more errors (fixed task: competitive $3.4 \pm 0.3$, cooperative $0.5 \pm 0.1$, mean errors $\pm \mathrm{SEM}, t_{30}=9.67$, $p<0.001$; novel place task: competitive $10.0 \pm 0.5$, cooperative $1.3 \pm 0.3$, mean errors \pm SEM, $t_{35}=15.57, p<0.001$; novel response task: competitive $5.4 \pm 0.5$, cooperative $0.4 \pm 0.2$, mean errors $\left.\pm \mathrm{SEM}, t_{16}=10.31, p<0.001\right)$ in agreement with previous studies (Schmidt et al., 2009; Jacobson et al., 2012).

However, no consistent differences in theta power were seen when waiting to perform a competitive or cooperative trial. No differences were found in the fixed task in the dHipp, nor vHipp (both $p>0.10$ ). In the novel place task a trend was seen in increased dHipp theta power when waiting to perform a competitive trial $\left(t_{(54)}=1.83, p=0.072\right)$, but not in the vHipp $\left(t_{(30)}=\right.$ $-0.32, p>0.10)$. In the novel response task theta power increased in the vHipp preceding cooperative trials $\left(t_{(25)}=2.13\right.$, $p<0.05)$, but not in the dHipp $\left(t_{(29)}=-0.23, p>0.10\right)$. The change in theta power was greater in vHipp than $\operatorname{dHipp}\left(t_{(25)}=\right.$ 2.72, $p<0.05$ ).

\section{Correct versus incorrect trials}

The effects of trial accuracy on theta power is currently unknown; some studies suggest theta power increases on correct trials (Jones and Wilson, 2005), whereas others report no change (Montgomery et al., 2009; Shirvalkar et al., 2010). Neither dHipp, nor vHipp theta power predicted trial accuracy in the fixed task or novel response task (all $p>0.10$ ). In the novel place task, theta power was greater preceding correct trials in the dHipp $\left(t_{(54)}=\right.$ $2.58, p<0.05)$, but not the vHipp $\left(t_{(30)}=-1.28, p>0.10\right)$. Not unexpectedly, the change in theta power was greater in the dHipp than vHipp $\left(t_{(83)}=3.26, p<0.01\right)$.

\section{Hippocampal-dependent versus independent trials}

Place strategies are believed to be hippocampal-dependent, while response strategies are hippocampal-independent (Packard and McGaugh, 1996). We found similar lesion effects on place trials using the present paradigm (Jacobson et al., 2012). However, in the fixed task anticipating/preparing to use a place strategy had no effect on theta power in neither the dHipp, nor the vHipp (both $p>0.10$ ). In the novel place task, planning to use place strategy did not affect vHipp theta power $\left(t_{(30)}=-0.80, p>\right.$ $0.10)$. However, there was a trend for increased dHipp theta power preceding the response trials $\left(t_{(54)}=1.90, p=0.063\right)$. In contrast, on the novel response task, planning to use a place strategy increased vHipp theta power $\left(t_{(25)}=-2.98, p<0.05\right)$, but not dHipp theta power $\left(t_{(29)}=-0.93, p>0.10\right)$.

In contrast to the numerous changes seen consistently across tasks (see above), trial difficulty, trial accuracy, and navigation strategy used resulted in minimal and variable effects between the dHipp and the vHipp and across tasks.

\section{Effects of set shifting}

To examine whether theta oscillations were modulated by the behavioral flexibility required for strategy switching we analyzed the first trial after a strategy switch (place to response or response to place) compared with steady-state trials (successive trials of the same strategy). Animals were cued regarding the upcoming trial strategy upon leaving the goal and progressing toward the next start location (i.e., during the control epoch). Therefore, we compared theta power on the control epoch on switch and steadystate trials during the fixed task (a task when animals were performing at asymptote and had no novel learning component).
Theta power in the dHipp was greater on switch than steadystate trials $\left(t_{(30)}=3.13, p<0.002\right)$, despite no differences in running speed $\left(t_{(30)}=1.39, p>0.08\right)$. This phenomenon was limited to the dHipp, as there were no differences between switch and steady-state trials in the vHipp $\left(t_{(17)}=0.27, p>0.10\right)$. Thus, despite the fact that navigation strategy had no effect on theta power (see above), switching between strategies resulted in greater theta power in the dHipp than consistently using the same navigation strategy.

\section{Discussion}

Rats were trained to continuously switch between place and response strategies in three tasks that differed in their hippocampal-dependent and independent components. Multiple dissociations between dHipp and vHipp theta were found across tasks: (1) theta frequency (peak) was higher in the dHipp. (2) Theta frequency increased during the decision epoch, particularly in the dHipp. (3) Theta power was related to behavior in opposite ways in the dHipp and the vHipp, increasing in the dHipp during the decision epoch and decreasing in the vHipp. This effect was strongest during the beginning of the training session for dHipp and later in the session for vHipp. (4) The relationship between running speed and theta power was uncoupled during the decision epoch, but only in the dHipp. (5) Theta coherence increased during the decision epoch within the dHipp on all tasks; however, coherence within the vHipp and between the dHipp and the vHipp increased solely on the task with new hippocampal learning. (6) Theta power was modulated by set shifting, a phenomenon limited to the dHipp.

\section{Theta frequency increased during decision-making}

Jeewajee et al. (2008) reported decreased theta frequency with environmental novelty. Computational models propose that the reduction seen in theta frequency in environmental novelty potentially results from increased acetylcholine release (Acquas et al., 1996) and may contribute to successful encoding (Aigner and Mishkin, 1986; Tang et al., 1997).

In this study, dHipp and vHipp theta frequency increased during the decision epoch, an effect generally larger in the dHipp and dissociable from running speed. Jeewajee et al. (2008) reported increased theta frequency across training sessions. We expanded on this by showing changes within day and limited to the purported decision-making epoch of the maze. Though the functional implications and mechanisms of changes in theta frequency have not been fully elucidated, we have previously shown that systemic injections of physiostigmine reduce theta frequency (Jacobson et al., 2013). Together, activity-dependent increases in theta frequency could reflect a shift away from the impact of cholinergic activation and may facilitate retrieval processes (Barry et al., 2012).

\section{Theta power and speed are uncoupled with cognitive demands in the dorsal hippocampus}

Do theta oscillations facilitate cognition, or are the changes in theta power seen simply an effect of running speed? Hippocampal theta power is positively correlated with running speed (Vanderwolf, 1969; Steward and Vanderwolf, 1987; Hinman et al., 2011), yet, it also shows changes with cognitive/mnemonic demands (Klimesch, 1999; Düzel et al., 2010). The correlation between theta power and running speed was uncoupled with increased cognitive demands in the dHipp. In contrast, this relationship was not affected by the cognitive aspects of the task in the vHipp. These results suggest that theta power does not simply 
reflect volitional movement (Kelemen et al., 2005), but the cognitive demands of a task as well.

\section{Theta power increased in the dorsal but decreased in the ventral hippocampus during decision-making}

Theta power in the dHipp increased during the decision-making epoch of the maze. This increase was seen regardless of whether the running speed was greater (i.e., fixed task), or similar (i.e., the other two tasks) to the control epoch speed; this is not surprising given that the speed power relationship was uncoupled during the decision epoch.

Theta oscillations may facilitate decision-making processes. Montgomery et al. (2009) demonstrated in rats trained on a hippocampal-dependent spatial alternation task that the maze region occupied by the rat (e.g., decision region) had a greater modulating effect on theta power than running speed. Specifically, theta power increased on the center arm of the maze, where the purported cognitive operations, such as memory retrieval and decision-making, were performed. To our knowledge, no study has previously examined the effects of navigation decisionmaking on vHipp theta. vHipp theta was also affected by decision-making; however, in the opposite manner, showing a decrease in theta power.

The increased dHipp theta power seen during decisionmaking attenuated within a training session as animals were learning a new task (acquisition on both the novel place and novel response tasks). This was also found at criterion in the novel place task, notably in this task, even at criterion, each day required the rat to learn a new place goal arm. In contrast, this was not seen during asymptotic performance in tasks that did require new learning, such as the fixed task and the novel response task. The decrease in vHipp theta did not follow this pattern. Together, these results suggest that the change in theta power reflects not only decision-making, but the learning as well.

\section{Effects of task difficulty and errors}

dHipp and vHipp theta power were differentially affected by the anticipated trial, when the animal was waiting to initiate the decision epoch. Although the results from the decision epochs were substantial and consistent across tasks, the data from this wait period was more variable. Despite increased variability, differences between dHipp and vHipp theta were apparent. Theta power increased in the dHipp, but not the vHipp, during competitive trials on the novel place task. Similarly, theta power increased in the dHipp preceding correct trials on the novel place task; however, this effect was not seen in the vHipp.

\section{Hippocampus-dependent learning did not affect theta power} Hippocampal "place" cells, which code for spatial location (O'Keefe and Dostrovsky, 1971; O'Keefe and Nadel, 1978), differentiate between place and response strategies (Eschenko and Mizumori, 2007; Schmidt et al., 2012). dHipp lesions impair place, but not response navigation on the current (Jacobson et al., 2012) and similar tasks (Packard and McGaugh, 1996). Similarly, disrupting theta oscillations results in spatial impairments (Winson, 1978; Shirvalkar et al., 2010) and human hippocampal activity increases during virtual navigation (Hartley et al., 2003; Iaria et al., 2003). Despite the above, in this study, neither dHipp nor vHipp theta power was affected by navigation strategy used. Immediate-early-gene studies have similarly failed to find differences in overall hippocampal activation between hippocampaldependent and independent navigation tasks (Guzowski et al., 2001; Schmidt et al., 2012). It is possible that rather than local inputs or principal cell activity, coactivity across a large region of hippocampus has functional implications.

\section{Set shifting modulated theta power in the dorsal but not the ventral hippocampus}

Switching between strategies resulted in greater theta power than consistently using the same navigation strategy. This effect was limited to the dHipp. Though strategy switching is generally believed to be supported downstream to the hippocampus, by the prefrontal cortices (Rich and Shapiro, 2009; Young and Shapiro, 2009), the current results suggest that the neural processes in the dHipp also reflect the cognitive demands of set shifting.

\section{Theta coherence increased in the dorsal hippocampus during decision-making}

Coherent oscillations provide common windows for inputs and outputs allowing for more effective communication (Fries, 2005). During the decision epoch theta coherence increased within the dHipp on all tasks. Conversely, theta coherence selectively increased within the vHipp and between the dHipp and the vHipp during the novel place task, the task with the greatest hippocampal demand/learning, but not in the fixed task, nor the novel response task. Notably the increased theta coherence between the dHipp and vHipp cannot be an epiphenomenon of increased power in both structures because this occurred at the same time as a decrease in vHipp theta power.

Our data are in accord and extends on previous studies that have shown increased theta coherence within dHipp during decision-making on spatial tasks (Montgomery et al., 2009). Similar studies have shown increased theta coherence during decision-making between the hippocampus and striatum (Decoteau et al., 2007), as well as the hippocampus and prefrontal cortex (Jones and Wilson, 2005; Benchenane et al., 2010). To our knowledge, no study has previously examined coherence in both the dHipp and Vhipp during decision-making on a spatial task.

\section{Concluding thoughts}

Our view of the hippocampus has evolved from a homogenous structure to one that dissociates along the septotemporal axis. The current study supports this distinction, showing multiple quantitative and qualitative differences in dHipp and vHipp theta oscillations. However, the current data also indicate the vHipp was quite responsive to the navigation task. vHipp theta frequency, power, and coherence were all affected by cognitive demands. These data are in agreement with others that show vHipp involvement in spatial learning (Ogren et al., 1996; Floresco et al., 1997; Schott et al., 1998; Ferbinteanu et al., 2003; de Hoz et al., 2003; Loureiro et al., 2012).

Perhaps the most intriguing finding was of coherence. Theoretically, a task demanding on hippocampal processes could be based on different functional components of the hippocampus working independently, each subregion processing different aspects of the task. The output from the subregions would get integrated elsewhere in the brain (presumably neocortex). Alternatively, the integration could take place within the hippocampus. The latter option would require synchronization throughout the hippocampus. The findings of increased coherence between the dHipp and the vHipp only on the spatial working memory task support this second option and suggest a large degree of cooperation throughout the hippocampus during information processing. 


\section{References}

Acquas E, Wilson C, Fibiger HC (1996) Conditioned and unconditioned stimuli increase frontal cortical and hippocampal acetylcholine release: effects of novelty, habituation, and fear. J Neurosci 16:3089-3096. Medline

Aigner TG, Mishkin M (1986) The effects of physostigmine and scopolamine on recognition memory in monkeys. Behav Neural Biol 45:81-87. Medline

Amaral D, Lavenex P (2007) Hippocampal neuroanatomy. In: The hippocampus book. Oxford: Oxford UP.

Barry C, Heys JG, Hasselmo M (2012) Possible role of acetylcholine in regulating spatial novelty effects on theta rhythm and grid cells. Front Neural Circuits 6:5. CrossRef Medline

Benchenane K, Peyrache A, Khamassi M, Tierney PL, Gioanni Y, Battaglia FP, Wiener SI (2010) Coherent theta oscillations and reorganization of spike timing in the hippocampal-prefrontal network upon leaning. Neuron 66:921-936. CrossRef Medline

Bullock TH, Buzsáki G, McClune MC (1990) Coherence of compound field potentials reveals discontinuities in the CA1-subiculum of the hippocampus in freely-moving rats. Neuroscience 38:609-619. CrossRef Medline

Buzsáki G (2002) Theta oscillations in the hippocampus. Neuron 33:325-340. CrossRef Medline

DeCoteau WE, Thorn C, Gibson DJ, Courtemanche R, Mitra P, Kubota Y, Graybiel AM (2007) Learning-related coordination of striatal and hippocampal theta rhythms during acquisition of a procedural maze task. Proc Natl Acad Sci U S A, 104:5644-5649. CrossRef Medline

de Hoz L, Knox J, Morris RG (2003) Longitudinal axis of the hippocampus: both septal and temporal poles of the hippocampus support water maze spatial learning depending on the training protocol. Hippocampus 13: 587-603. CrossRef Medline

Dolorfo CL, Amaral DG (1998) Entorhinal cortex of the rat: topographic organization of the cells of origin of the perforant path projection to the dentate gyrus. J Comp Neurol 398:25-48. CrossRef Medline

Düzel E, Penny WD, Burgess N (2010) Brain oscillations and memory. Curr Opin Neurobiol 20:143-149. CrossRef Medline

Efron B, Tibshirani RJ (1993) An introduction to the bootstrap. New York: Chapman and Hall.

Eschenko O, Mizumori SJ (2007) Memory influences on hippocampal and striatal neural codes: effects of a shift between task rules. Neurobiol Learn Mem 87:495-509. CrossRef Medline

Fanselow MS, Dong HW (2010) Are the dorsal and ventral hippocampus functionally distinct structures? Neuron 65:7-19. CrossRef Medline

Ferbinteanu J, Ray C, McDonald RJ (2003) Both dorsal and ventral hippocampus contribute to spatial learning in Long-Evans rats. Neurosci Lett 345:131-135. CrossRef Medline

Floresco SB, Seamans JK, Phillips AG (1997) Selective roles for hippocampal, prefrontal cortical and ventral striatal circuits in radial-arm maze tasks with or without a delay. J Neurosci 17:1880-1890. Medline

Fries P (2005) A mechanism for cognitive dynamics: neural communication through neural coherence. Trends Cogn Sci 9:474-480. CrossRef Medline

Guzowski JF, Setlow B, Wagner EK, McGaugh JL (2001) Experiencedependent gene expression in the rat hippocampus after spatial learning: a comparing the immediate-gene Arc, c-fos, and zif268. J Neurosci 21: 5089-5098. Medline

Hartley T, Maguire EA, Spiers HJ, Burgess N (2003) The well-worn route and the path less traveled: distinct neural bases of route following and way finding in humans. Neuron 37:877-888. CrossRef Medline

Hasselmo ME (2005) What is the function of hippocampal theta rhythm? Linking behavioral data to phasic properties of filed potentials and unit recording data. Hippocampus 15:936-949. CrossRef Medline

Hinman JR, Penley SC, Long LL, Escabí MA, Chrobak JJ (2011) Septotemporal variation in dynamics of theta: speed and habituation. J Neurophysiol 105:2675-2686. CrossRef Medline

Hinman JR, Penley SC, Escabí MA, Chrobak JJ (2013) Ketamine disrupts theta synchrony across the septotemporal axis of the CA1 region of the hippocampus. J Neurophysiol 109:570-579. CrossRef Medline

Hyman JM, Wyble BP, Goyal V, Rossi CA, Hasselmo ME (2003) Stimulation in hippocampal region CA1 in behaving rats yields long-term potentiation when delivered to the peak of theta and long-term depression when delivered to the trough. J Neurosci 23:11726-11731. Medline

Iaria G, Petrides M, Dagher A, Pike B, Bohbot VD (2003) Cognitive strate- gies dependent on the hippocampus and caudate nucleus in human navigation: variability and change with practice. J Neurosci 23:5945-5952. Medline

Jacobson TK, Gruenbaum BF, Markus EJ (2012) Extensive training and hippocampal or striatum lesions: effect on place and response strategies. Physiol Behav 105:645-652. CrossRef Medline

Jacobson TK, Howe MD, Schmidt B, Hinman JR, Escabí M, Markus EJ (2013) Hippocampal theta, gamma, and theta(-)-gamma coupling: effects of aging, environmental change, and cholinergic activation. J Neurophysiol 10.1152/jn.00409.2012<zpmid $>23303862<$ /zpmid $><$ bx $>$

$<$ zrefs\%3B28> Jeewajee A, Lever C, Burton S, O'Keefe J, Burgess $\mathrm{N}<$ zens $>(2008)<$ zens $>$ Environmental novelty is signaled by reduction of the hippocampal theta frequency. Hippocampus 18:340-348. CrossRef Medline

Jones MW, Wilson MA (2005) Theta rhythms coordinate hippocampalprefrontal interactions in a spatial memory task. PLoS Biol 3:e402. CrossRef Medline

Jung MW, Wiener SI, McNaughton BL (1994) Comparison of spatial firing characteristics of units in dorsal and ventral hippocampus of the rat. J Neurosci 14:7347-7356. Medline

Kahana MJ, Seelig D, Madsen JR (2001) Theta returns. Curr Opin Neurobiol 11:739-744. CrossRef Medline

Kaplan R, Doeller CF, Barnes GR, Litvak V, Düzel E, Bandettini PA, Burgess N (2012) Movement-related theta rhythm in humans: coordinating self-directed hippocampal learning. PLoS Biol 10:e1001267. CrossRef Medline

Kelemen E, Morón I, Fenton AA (2005) Is the hippocampal theta rhythm related to cognition in a non-locomotor place recognition task? Hippocampus 15:472-479. CrossRef Medline

Kjelstrup KB, Solstad T, Brun VH, Hafting T, Leutgeb S, Witter MP, Moser EI, Moser MB (2008) Finite scale of spatial representation in the hippocampus. Science 4:140-143. CrossRef Medline

Klimesch W (1999) EEG alpha and theta oscillations reflect cognitive and memory performance: a review and analysis. Brain Res Rev 29:169-195. CrossRef Medline

Loureiro M, Lecourtier L, Engeln M, Lopez J, Cosquer B, Geiger K, Kelche C, Cassel JC, Pereira de Vasconcelos A (2012) The ventral hippocampus is necessary for expressing a spatial memory. Brain Struct Funct 217:93106. CrossRef Medline

Masuoka T, Fujii Y, Kamei C (2006) Participation of hippocampal theta rhythm in memory formation for an eight-arm radial maze task in rats. Brain Res 1103:159-163. CrossRef Medline

M'Harzi M, Jarrard LE (1992) Effects of medial and lateral septal lesions on acquisition of a place and cue radial maze task. Behav Brain Res 49:159 165. CrossRef Medline

Mizumori SJ, Perez GM, Alvarado MC, Barnes CA, McNaughton BL (1990) Reversible inactivation of the medial septum differentially affects two forms of learning in rats. Brain Res 528:12-20. CrossRef Medline

Montgomery SM, Betancur MI, Buzsáki G (2009) Behavior-dependent coordination of multiple theta dipoles in the hippocampus. J Neurosci 29: 1381-1394. CrossRef Medline

Moser MB, Moser EI (1998) Functional differentiation in the hippocampus. Hippocampus 8:608-619. CrossRef Medline

Ogren SO, Kehr J, Schött PA (1996) Effects of ventral hippocampal galanin on spatial learning and on in vivo acetylcholine release in the rat. Neuroscience 75:1127-1140. CrossRef Medline

O'Keefe J, Burgess N (1999) Theta activity, virtual navigation and the human hippocampus. Trends Cogn Sci 3:403-406. CrossRef Medline

O’Keefe J, Dostrovsky J (1971) The hippocampus as a spatial map. Preliminary evidence from unit activity in the freely moving rat. Brain Res 34: 171-175. CrossRef Medline

O’Keefe J, Nadel L (1978) The hippocampus as a cognitive map. Clarendon, Oxford.

Packard MG, McGaugh JL (1996) Inactivation of hippocampus or caudate nucleus with lidocaine differentially affects expression of place and response learning. Neurobiol Learn Mem 65:65-72. CrossRef Medline

Patel J, Fujisawa S, Berényi A, Royer S, Buzsáki G (2012) Traveling theta waves along the entire septotemporal axis of the hippocampus. Neuron 75:410-417. CrossRef Medline

Paxinos G, Watson C (1986) The rat brain in stereotaxic coordinates, Ed 2. Sydney: Academic.

Penley SC, Hinman JR, Sabolek HR, Escabí MA, Markus EJ, Chrobak JJ 
(2012) Theta and gamma coherence across the septotemporal axis during distinct behavioral states. Hippocampus 22:1164-1175. CrossRef Medline

Raghavachari S, Kahana MJ, Rizzuto DS, Caplan JB, Kirschen MP, Bourgeois B, Madsen JR, Lisman JE (2001) Gating of human theta oscillations by a working memory task. J Neurosci 21:3175-3183. Medline

Rich EL, Shapiro M (2009) Rat prefrontal cortical neurons selectively code strategy switches. J Neurosci 29:7208-7219. CrossRef Medline

Risold PY, Swanson LW (1996) Structural evidence for functional domains in the rat hippocampus. Science 272:1484-1486. CrossRef Medline

Roark RM, Escabí MA (1999) B-spline design of maximally flat and prolate spheroidal-type FIR filters. IEEE Trans Sig Proc 47:701-716. CrossRef

Royer S, Sirota A, Patel J, Buzsáki G (2010) Distinct representations and theta dynamics in dorsal and ventral hippocampus. J Neurosci 30:1777-1787. CrossRef Medline

Sabolek HR, Penley SC, Hinman JR, Bunce JG, Markus EJ, Escabí M, Chrobak JJ (2009) Theta and gamma coherence along the septotemporal axis of the hippocampus. J Neurophysiol 101:1192-1200. CrossRef Medline

Satvat E, Schmidt B, Argraves M, Marrone DF, Markus EJ (2011) Changes in task demands alter the pattern of zif268 expression in the dentate gyrus. J Neurosci 31:7163-7167. CrossRef Medline

Schmidt B, Jacobson TK, Markus E (2009) Hippocampal and striatal dependent navigation: sex differences are limited to acquisition. Horm Behav 56:199-205. CrossRef Medline

Schmidt B, Satvat E, Argraves M, Markus EJ, Marrone DF (2012) Cognitive demands preferentially drive reorganization in hippocampal dorsodistal CA1. Hippocampus 22:2114-2126. CrossRef Medline

Schmidt B, Papale A, Redish AD, Markus EJ (2013) Conflict between place and response navigation strategies: effects on vicarious trial and error (VTE) behaviors. Learn Mem 20:130-138. CrossRef Medline

Schott PA, Bjelke B, Ogren SO (1998) Distribution and kinetics of galanin infused into the ventral hippocampus of rat: relationship to spatial learning. Neuroscience 83:123-136. CrossRef Medline

Shin J (2011) The interrelationship between movement and cognition: theta rhythm and the p300 event-related potential. Hippocampus 21:744-752. CrossRef Medline

Shirvalkar PR, Rapp PR, Shapiro ML (2010) Bidirectional changes to hippocampal-gamma comodulation predict memory for recent spatial episodes. Proc Natl Acad Sci U S A 107:7054-7059. CrossRef Medline

Stewart DJ, Vanderwolf CH (1987) Hippocampal rhythmical slow activity following ibotenic acid lesions of the septal region: I. Relations to behavior and effects of atropine and urethane. Brain Res 423:88-100. CrossRef Medline

Tang Y, Mishkin M, Aigner TG (1997) Effects of muscarinic blockade in perirhinal cortex during visual recognition. Proc Natl Acad Sci U S A, 94:12667-12669. CrossRef Medline

Tort ABL, Komorowki RW, Manns JR, Kopell NJ, Eichenbaum H (2009) Theta-gamma coupling increases during the learning of item-context associations. Proc Natl Acad Sci U S A 106:20942-20947. CrossRef Medline

Vanderwolf $\mathrm{CH}$ (1969) Hippocampal electrical activity and voluntary movement in the rat. Electroencephalogr Clin Neurophysiol 26:407-418. CrossRef Medline

Voss JL, Gonsalves BD, Federmeier KD, Tranel D, Cohen NJ (2011) Hippocampal brain-network coordination during volitional exploratory behavior enhances learning. Nat Neurosci 14:115-120. CrossRef Medline

Welch PD (1967) The use of fast Fourier transform of the estimation of power spectra: a method based on time averaging over short, modified periodograms. IEEE Trans Audio Electroacoust 15:70-73. CrossRef

Winson J (1978) Loss of hippocampal theta rhythm results in spatial memory deficit in the rat. Science 201:160-163. CrossRef Medline

Young JJ, Shapiro ML (2009) Double dissociation and hierarchical organization of strategy switches and reversals in the rat PFC. Behav Neurosci 123:1028-1035. CrossRef Medline 